\title{
Is there an association between upper limb claudication and handgrip strength in Takayasu arteritis?
}

\author{
A.M. dos Santos, R.G. Misse, I.B.P. Borges, R.M.R. Pereira, S.K. Shinjo \\ Division of Rheumatology, Faculdade de Medicina FMUSP, Universidade de Sao Paulo, SP, Brazil (BR)
}

\begin{abstract}
SUMMARY
Limb vascular claudication and hand muscle weakness are common symptoms of Takayasu arteritis (TAK). However, no studies have correlated these two symptoms. Therefore, the aim of the study was to evaluate handgrip strength and its correlation with both upper-limb vascular claudication and imaging of the vessels. This cross-sectional study compared 36 patients with TAK who were matched by age, gender, and body mass index with 36 individuals without TAK (CTR). Hand strength (assessed with handgrip dynamometer), functional capacity (Health Assessment Questionnaire, HAQ), upper-limb vascular claudication symptoms (patients' selfreported form), and disease activity (Indian Takayasu Clinical Activity Score [ITAS] 2010; Physician Global Assessment [PGA], C-reactive protein, and erythrocyte sedimentation rate) were evaluated as well as vessel imaging (e.g., angiotomography or angioresonance) and blood pressure.

The median age of the patients was 42.0 years (35.5-51.5 years), whereas the mean disease duration was $13.1 \pm 6.8$ years. No patient had active disease. Compared to the CTR, the patients with TAK showed reduced strength in the left-hand $(22.9 \pm 5.9$ vs $26.3 \pm 5.6 \mathrm{~kg} ; \mathrm{p}=0.014)$ and increased HAQ scores [0.50 $(0.12-0.87)$ vs $0.00(0.00-0.00) ; \mathrm{p}<0.001]$. Both groups had comparable blood pressure. Among patients with TAK, lefthand strength was inversely correlated with HAQ (Spearman correlation: rho=-0.584; $\mathrm{p}<0.001$ ) and positively correlated with right-hand strength (rho=0.644; $\mathrm{p}<0.001$ ). Moreover, neither hand's strengths in the patients were correlated with subclavian stenosis imaging, blood pressure or limb vascular claudication.

The reduction of strength in the upper left limb is inversely related to the functional capacity (HAQ score) of TAK. This reduction appears unrelated to classical vascular claudication, vessel imaging or blood pressure.
\end{abstract}

Key words: Strength, functional capacity, hand grip, limb claudication, systemic vasculitis.

Reumatismo, 2020; 72 (4): 197-206

\section{INTRODUCTION}

akayasu arteritis (TAK) is a primary systemic vasculitis that affects the large arterial vessels and their main branches (1-3). It is a rare disease that mainly affects young women $(1,2)$. The main characteristic of TAK is chronic vascular inflammation, leading to the presence of stenosis, occlusions, ectasias and/or aneurysms and consequently producing pulse differences between the limbs, as well as vascular claudication (3-5). The latter is a relatively common symptom in TAK patients and may even lead to discomfort and limitations to routine activities (3). Another recurrent condition in patients with TAK is decreased muscle strength and aerobic ca- pacity (6-8). All of these factors can also limit daily activities, and impair quality of life and function. This situation may also lead to decreased handgrip, although no studies in the literature have shown this correlation yet.

In medical practice, symptom assessment lacks quantitative tools and is based primarily on physician experience, patient self-reporting and questionnaires, making it difficult to assess the true extent of symptoms or disease activity, specifically the reduction in muscle strength (9-12). In this context, the handgrip dynamometer provides a direct measure, besides being widely used in other autoimmune diseases, and may facilitate the assessment of both upper limb weakness and possible differences in $\overline{\text { Corresponding author: }}$ Samuel Katsuyuki Shinjo Laboratorio de Miopatias Inflamatorias, 3 andar, room 3184

Division of Rheumatology,

Faculdade de Medicina Universidade de Sao Paulo, CEP 01246-903

Cerqueira Cesar, SP, Brazil E-mail: samuel.shinjo@usp.br 
strength resulting from long-term vascular claudication $(13,14)$.

Although there is no scientific evidence to date, handgrip strength may have an inverse relationship with the presence of vascular anatomical changes (arterial stenosis or occlusions) and vascular claudication, which in turn may corroborate the damage to activities of daily living and the functional capacity. Therefore, the primary objective of this study was to evaluate upper limb handgrip strength in TAK patients. The secondary objective was to evaluate possible correlations of handgrip strength, upper limb vascular claudication, blood pressure and vascular changes seen by imaging (e.g., angiotomography of blood vessels) as well as possible associations between vascular symptoms and imaging findings. The final objective was to measure the symptoms' interference with these patients' functional capacity.

\section{PATIENTS AND METHODS}

This cross-sectional, single-center study was conducted between 2018 and 2019. Initially, 90 patients with TAK who met three or more of the six items of the modified 1990 American College of Rheumatology (ACR) classification criteria for TAK were evaluated (3). Instead of the arteriogram abnormality criterion, we considered abnormal angiotomography or angioresonance images of large arterial vessels and their main branches.

This study was approved by the local Ethics Committee (CAAE 89386618.0.0000. 0068) and all participants signed an informed consent form. The study met all ethical criteria for conducting human studies (15). Patients who had sequelae related to cerebrovascular accidents, neurogenic claudication, fibromyalgia, overlap syndromes, or other diseases or conditions that could have affected the analyses of grip strength were excluded.

Eligible patients went through the following steps, shown in Figure 1. The following information was collected from patients' interviews. If necessary, additional pa- tients' data were obtained from electronic medical records:

- Age, disease duration, body mass index (BMI);

- Comorbidities: diabetes mellitus was defined when the fasting plasma glucose test was $\geq 126 \mathrm{mg} / \mathrm{dL}$ and/or the result of the oral glucose tolerance test $\geq 200 \mathrm{mg} /$ $\mathrm{dL}$, or specific drug treatment was present $(16,17)$; systemic arterial hypertension was considered when blood pressure had systolic values $\geq 130 \mathrm{mmHg}$ and/or diastolic values $\geq 85 \mathrm{mmHg}$, or specific drug treatment was present (18); dyslipidemia was defined when plasma total cholesterol $\geq 200 \mathrm{mg} / \mathrm{dL}$, HDL-cholesterol $\leq 50 \mathrm{mg} / \mathrm{dL}$, LDL-cholesterol $\geq 130 \mathrm{mg} /$ $\mathrm{dL}$, triglycerides $\geq 150 \mathrm{mg} / \mathrm{dL}$, or specific drug treatment was present (19);

- Previous and current medications: glucocorticoids, immunosuppressive drugs;

- Laboratory: erythrocyte sedimentation rate $(E S R)$ (reference value $<10 \mathrm{~mm} / 1^{\text {st }}$ hour, by automated Westergren method) and C-reactive protein (CRP) (reference value $<5.0 \mathrm{mg} / \mathrm{L}$, by immunoturbidimetric method);

- Vessel imaging examinations (computed tomography angiography or magnetic resonance angiography) performed within four months before or after the patients' inclusion in the present study;

- Arterial stenosis was defined when there was more than $50 \%$ of vessel diameter reduction seen in computed tomography angiography or magnetic resonance angiography;

- Vascular claudication was defined as discomfort, pain, tightness, heaviness, cramping, or weakness related to arms. These symptoms subside with rest exercise;

- Questionnaires. The functional capacity through the Health Assessment Questionnaire (HAQ) (20), lower limb vascular claudication through The Edinburgh Claudication Questionnaire (ECQ) (21), and vascular claudication of the upper limbs, based patient's self-reports;

- Blood pressure assessment (TAK and CTR): To measure blood pressure, all of the evaluated patients remained seated 
and rested for 5 minutes before starting the measurement. The arm to be measured remained supported and extended at the height of the sternum, and the cuff was positioned around the arm and correctly adjusted. Systolic pressure was determined by the first Korotkoff phase, and diastolic pressure by the fifth phase $(22,23)$;

- Disease activity was defined according to the Indian Takayasu Clinical Activity Score (ITAS) - 2010 translated and validated to the Portuguese language (11, 12). The disease was considered active when the value obtained from the questionnaire had $\geq 2$ points. Moreover, Physician Global Assessment (PGA, classified in active, grumbling/persistent, or inactive), CRP and ESR were also analyzed;

- Handgrip assessment (TAK and CTR): Handgrip was assessed using a Crown Manual dynamometer (Industrial Technique Oswaldo Filizola, São Paulo, SP, Brazil). The patients remained in the standing position during the test, with arms extended and aligned with the trunk. They used their maximum strength one hand at a time, for $10 \mathrm{sec}-$ onds on each hand, with a recovery period of 60 to 90 seconds between each test. This procedure was performed three times in each hand, that is, one familiarization and two valid tests. Participants were verbally motivated during each contraction. The highest value found was considered the maximum handgrip strength, respecting the coefficient of variation of $0.5 \%$, the same day period and the evaluator (24). In addition, we calculated the ratio between the non-dominant and dominant handgrip strength of all individuals (e.g., handgrip ratio $=$ non-dominant hand $/$ dominant hand) (25).

The control (CTR) group was composed of patients' relatives or employees from our tertiary center, who were age- and gendermatched to TAK patients. In addition, individuals with sequelae related to stroke, neurogenic claudication, fibromyalgia, systemic autoimmune diseases or other diseases or conditions that could have affected the analyses of grip strength were excluded. The following information was collected:

- Comorbidities (e.g., diabetes mellitus, systemic arterial hypertension, dyslipidemia);

- Questionnaires. The functional capacity through the HAQ (20).

Statistical analysis. Data distribution was determined by the Shapiro-Wilk test, from which normal data were expressed as mean and standard deviation. Data with asymmetric distribution were expressed as median (interquartile $25^{\text {th }}-75^{\text {th }}$ ). Categorical data were expressed as a percentage (\%) and differences were analyzed by Fisher's test. The existence of differences in quantitative variables with normal distribution was analyzed with the Student's $t$ test. For quantitative variables with asymmetric distribution, the Mann - Whitney U test was used (26). The correlation between variables with symmetrical distribution was analyzed with Pearson's test and variables with asymmetric distribution with Spearman's $\rho$ coefficient. Additionally, the pointbiserial correlation $(r \mathrm{pb})$ was used when one variable was continuous and the other dichotomous. In addition, the correlations were classified as low $(<0.333)$, moderate (between 0.333 and 0.666 ) or strong $(>0.666)$. Associations between two categorical variables were analyzed using Fisher's exact test. Differences were considered statistically significant when $\mathrm{p}$ values $<0.05$. Analyses were performed with GraphPad Prism ${ }^{\circledR}$ software version 6.01 for Windows (San Diego, California, USA).

\section{RESULTS}

Thirty-six $(40.0 \%)$ of the 90 patients were included and matched for gender, age, and BMI with 36 CTR (Figure 1). All of the patients were female, with median age of 42.0 years (35.5-51.5 years), BMI of 28.1 $\mathrm{kg} / \mathrm{m}^{2}\left(22.4-29.7 \mathrm{~kg} / \mathrm{m}^{2}\right)$ and mean disease duration of $13.1 \pm 6.8$ years.

At the time of the evaluations, no patient had active disease, according to their ITAS2010 scores and PGA. In addition, pa- 


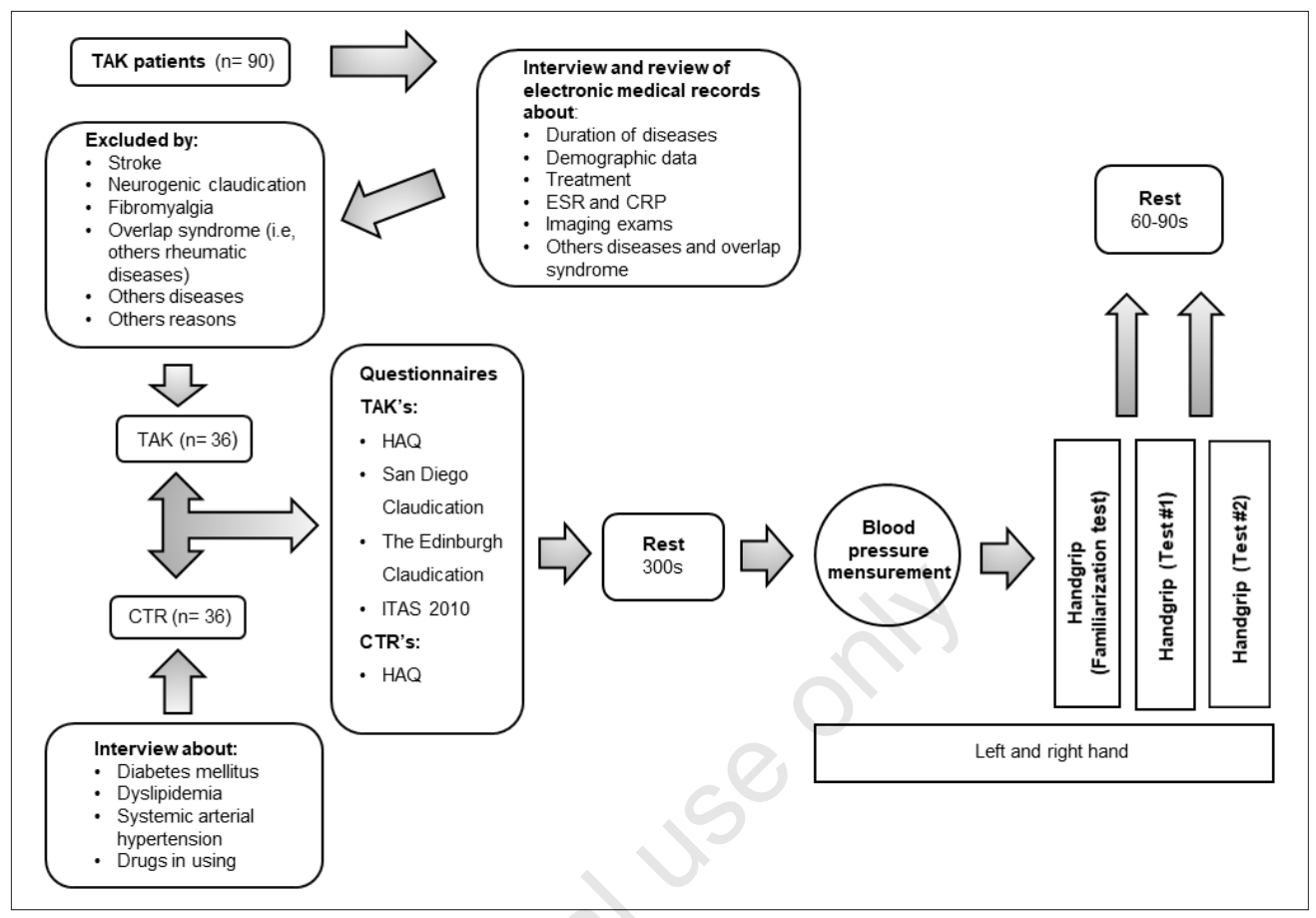

Figure 1 - Flowchart of the present study. CRP, C-reactive protein; CTR, control group; ESR, erythrocyte sedimentation rate; HAQ, Health Assessment Questionnaire; ITAS, Indian Takayasu Activity Index; REST, recovery; TAK, Takayasu arteritis.

tients had higher HAQ values when compared to the CTR group [0.50 (0.12-0.87) vs. $0.00(0.00-0.00) ; \mathrm{p}<0.001]$ (Table I).

Vascular claudication was observed in $11(30.5 \%)$ and $16(44.4 \%)$ patients in the right and left upper limbs, respectively. In 9 patients $(25.0 \%)$, vascular claudication was simultaneously present in both upper limbs. Regarding the vascular imaging findings, $13(36.1 \%)$ and $15(41.7 \%)$ patients presented stenosis in the right and left subclavian arteries, respectively. Nine patients $(25 \%)$ had stenosis in both subclavian arteries. Patients and CTR showed similar systolic and diastolic blood pressure assessed in both upper limbs (Table I).

Six $(16.6 \%)$ patients were using glucocorticoids (prednisone) $<20 \mathrm{mg} / \mathrm{day}$. In addition, $16(44.5 \%)$ patients used one or more immunosuppressive drugs (Table I).

Higher prevalence of dyslipidemia and systemic arterial hypertension (all patients with drug treatments) was found in TAK patients when compared to the CTR group, while the distribution of diabetes mellitus was similar in both groups (Table I).

The patients and CTR were mostly righthanded. In addition, they had similar righthand-grip strength. However, in the left hand, the patients presented reduced strength when compared to the CTR $(22.9 \pm 5.9 \mathrm{~kg} v s$. $26.3 \pm 5.6 \mathrm{~kg}, \mathrm{p}=0.014)$, but with comparable values in the ratio of hand grip strength (Table II and Figure 2). Still, the difference between patients' right and left handgrip strength was greater than $10 \%$.

The patients' HAQ presented a moderate correlation with the left-handgrip strength and the handgrip strength ratio (Figure 3 ). In addition, a moderate correlation between the grip strengths in both hands and between left hand strength and the hand grip strength ratio was seen (Table III). No correlations were found between handgrip strength and subclavian artery stenosis, upper limb claudication, handgrip strength ratio, or blood pressure (Table III).

Moreover, an association was found between bilateral vascular claudication and 
Table I - Demographic features, disease status, drug treatment and comorbidities of patients with Takayasu arteritis. Comparison with control group.

\begin{tabular}{|c|c|c|c|}
\hline & TAK $(n=36)$ & CTR $(n=36)$ & Valore $\mathrm{p}$ \\
\hline Age (years) & $42.0(35.5-51.5)$ & $41.5(35.0-53.7)$ & 0.883 \\
\hline Time of disease (years) & $13.1 \pm 6.8$ & - & - \\
\hline Body mass index $\left(\mathrm{kg} / \mathrm{m}^{2}\right)$ & $28.1(22.4-29.7)$ & $24.2(22.7-28.7)$ & 0.107 \\
\hline \multicolumn{4}{|l|}{ Disease status } \\
\hline HAQ $(0.00-3.00)$ & $0.50(0.10-0.90)$ & $0.00(0.00-0.00)$ & $<0.001$ \\
\hline Diseases activity (ITAS2010) & 0 & - & - \\
\hline $\mathrm{ESR}$ (mm/1st hour) & $18.5(10.2-39.2)$ & - & - \\
\hline $\mathrm{CRP}(\mathrm{mg} / \mathrm{L})$ & $3.3(1.3-7.7)$ & - & - \\
\hline \multicolumn{4}{|l|}{ Physician global assessment } \\
\hline Active & 0 & & \\
\hline Grumbling or persistent & 0 & & +1 \\
\hline Inactive & $36(100)$ & & $a+2$ \\
\hline \multicolumn{4}{|l|}{ Claudication: upper limbs } \\
\hline Both limbs & $9(25.0)$ & - & - \\
\hline Right limb & $11(30.6)$ & $\infty$ & - \\
\hline Left limb & $16(44.5)$ & $-\infty$ & - \\
\hline \multicolumn{4}{|l|}{ Vessel imaging exams } \\
\hline Both subclavian artery stenosis & $10(27.8)$ & - & - \\
\hline Right subclavian artery stenosis & $13(36.1)$ & $-20-$ & - \\
\hline Left subclavian artery stenosis & $15(41.7)$ & - & - \\
\hline \multicolumn{4}{|l|}{ Systolic blood pressure } \\
\hline Right upper limb (mmHg) & $121(93-142)$ & $113(105-125)$ & 0.059 \\
\hline Left upper limb (mmHg) & $121(107-146)$ & $110(103-120)$ & 0.255 \\
\hline Diastolic blood pressure & 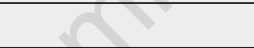 & & \\
\hline Right upper limb (mmHg) & $74(65-90)$ & $75(70-8)$ & 0.870 \\
\hline Left upper limb (mmHg) & $75(65-86)$ & $75(69-81)$ & 0.766 \\
\hline \multicolumn{4}{|l|}{ Treatment } \\
\hline Prednisone & - & - & - \\
\hline Current use (\%) & $6(16.7)$ & - & - \\
\hline Current dose (mg/day) & $5 ; 7.5 ; 10 ; 10 ; 10 ; 20$ & - & - \\
\hline IS or immunobiological & - & - & - \\
\hline Current use of one or more & $16(44.4)$ & - & - \\
\hline Azathioprine & $4(11.1)$ & - & - \\
\hline Abatacept & $1(2.8)$ & - & - \\
\hline Methotrexate & $6(16.7)$ & - & - \\
\hline Mycophenolate mofetil & $1(2.8)$ & - & - \\
\hline Leflunomide & $5(13.9)$ & - & - \\
\hline Infliximab & $4(11.1)$ & - & - \\
\hline Tocilizumab & $1(2.8)$ & - & - \\
\hline \multicolumn{4}{|l|}{ Traditional risk factors for CVD } \\
\hline Dyslipidemia & $18(50.0)$ & $3(8.3)$ & $<0.001$ \\
\hline Systemic arterial hypertension & $25(69.4)$ & $5(13.9)$ & $<0.001$ \\
\hline Diabetes mellitus & $2(5.6)$ & $2(5.6)$ & 1 \\
\hline
\end{tabular}

Data expressed as mean standard deviation; median (interquartile 25th-75th) or frequency (\%). CRP, C-reactive protein; CTR, control group; CVD, cardiovascular diseases; ESR, erythrocyte sedimentation rate; HAQ, Health Assessment Questionnaire; IS, immunosuppressive; ITAS, Indian Takayasu Activity Index; TAK, Takayasu arteritis. 
Table II - Dominant hand, handgrip strengths and ratio in patients with Takayasu arteritis and control group.

\begin{tabular}{|l|c|c|c|}
\hline & TAK $(\mathbf{n}=36)$ & CTR $(\mathbf{n}=36)$ & Valore $\mathbf{p}$ \\
\hline Dominant hand right (\%) & $35(97.2)$ & $34(94.4)$ & $>0.999$ \\
\hline Grip strength in right hand $(\mathrm{kg})$ & $26.2 \pm 6.2$ & $27.7 \pm 5.2$ & 0.254 \\
\hline Grip strength in left hand $(\mathrm{kg})$ & $22.9 \pm 5.9$ & $26.3 \pm 5.6$ & 0.014 \\
\hline Grip strength ratio & $0.88(0.79-0.95)$ & $0.95(0.88-1.00)$ & 0.006 \\
\hline
\end{tabular}

CTR, control group; Grip strength ratio, ratio between non-dominant hand and dominant hand; TAK, Takayasu arteritis.

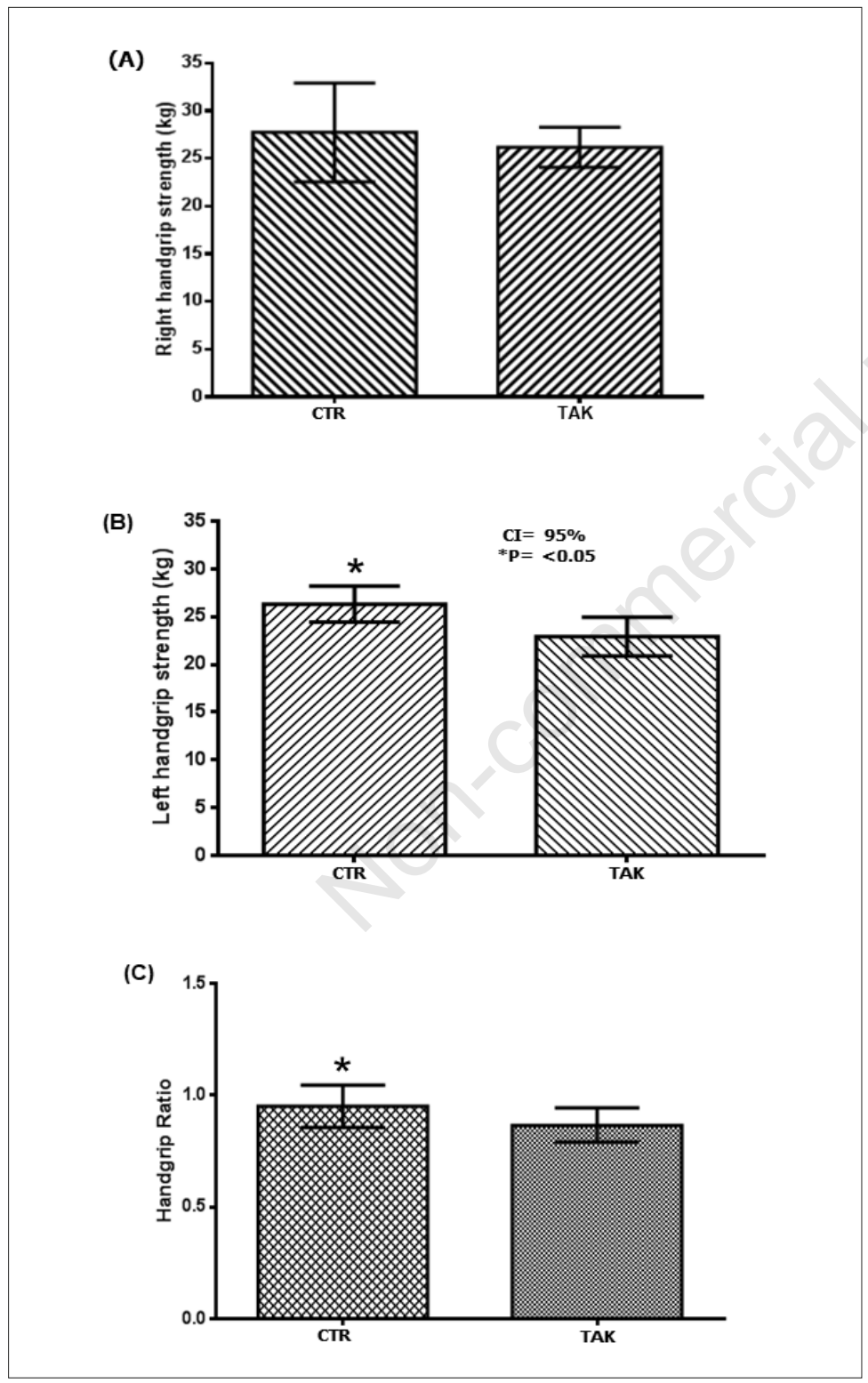

Figure 2 - Handgrip strength in patients with Takayasu arteritis and control group. $\mathrm{Cl}$, confidence interval; CTR, control group; Handgrip ratio, ratio between non-dominant hand strength and dominant hand strength; TAK, Takayasu arteritis.
(A)

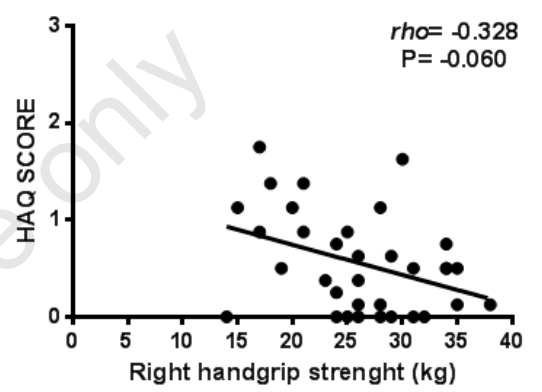

(B)

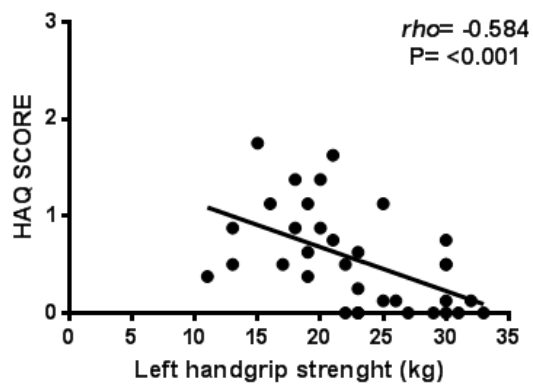

(C)

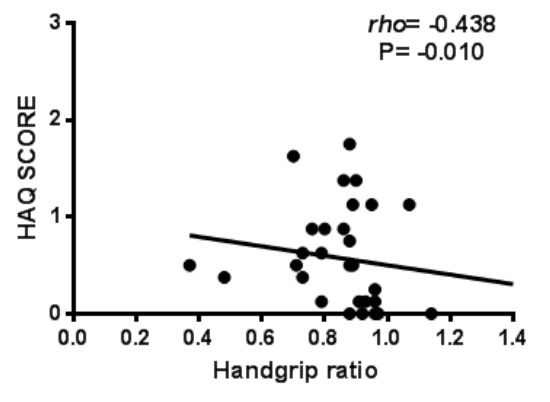

Figure 3 - Correlation between Health Assessment Questionnaire score and hand grip strength in patients with Takayasu arteritis. Handgrip ratio, ratio between non-dominant hand and dominant hand; $H A Q$, Health Assessment Questionnaire; TAK, Takayasu arteritis. 
left subclavian artery stenosis, but without any other unilateral or contralateral association (Table IV).

\section{DISCUSSION AND CONCLUSIONS}

The present study shows that patients with TAK have lower handgrip strength in the left upper limb and a lower ratio between their dominant and non-dominant hand. Moreover, reduction of strength was inversely correlated with functional capacity and was not correlated with limb claudication, arterial pressure or subclavian artery stenosis. Additionally, we found an association between simultaneous vascular claudication (e.g., both sides) and stenosis in the left subclavian, with no further associations between the imaging examinations and vascular symptoms.

Although TAK is considered a rare systemic vasculitis, we included an expressive sample of TAK patients who were also matched by gender, age and BMI with the control group. Furthermore, we provided detailed information about disease status and drug use.

Our patients with TAK showed a significant reduction in strength in the left hand.

Table III - Correlation among handgrip strength, $\mathrm{HAQ}$, claudication in upper limbs, stenosis in upper limbs and blood pressure in patients with Takayasu arteritis.

\begin{tabular}{|c|c|c|c|c|c|c|}
\hline \multirow[b]{2}{*}{ Variables } & \multicolumn{2}{|c|}{ Right handgrip } & \multicolumn{2}{|c|}{ Left handgrip } & \multicolumn{2}{|c|}{ Handgrip ratio } \\
\hline & $\mathrm{rho} / \mathrm{r}_{\mathrm{pb}}$ & $\mathrm{p}$ & rho/r $\mathrm{rbb}_{\mathrm{pb}}$ & $\mathrm{p}$ & $\mathrm{rho} / \mathrm{r}_{\mathrm{pb}}$ & $p$ \\
\hline $\mathrm{HAQ}$ & -0.328 & 0.060 & -0.584 & $<0.001$ & -0.438 & 0.010 \\
\hline Claudication in upper right limb & -0.092 & 0.601 & -0.174 & 0.317 & -0.058 & 0.714 \\
\hline Claudication in upper left limb & 0.051 & 0.770 & -0.333 & 0.050 & 0.490 & 0.003 \\
\hline Stenosis in right subclavian & -0.085 & 0.627 & 0.181 & 0.298 & 0.209 & 0.228 \\
\hline Stenosis in left subclavian & -0.179 & 0.304 & 0.053 & 0.761 & 0.057 & 0.747 \\
\hline Right handgrip & $-\quad$ & - & 0.586 & $<0.001$ & -0.168 & 0.334 \\
\hline Left handgrip & 0.586 & $<0.001$ & - & - & 0.505 & 0.002 \\
\hline \multicolumn{7}{|l|}{ Systolic blood pressure (mmHg) } \\
\hline Right upper limb & -0.133 & 0.453 & 0.024 & 0.892 & 0.063 & 0.723 \\
\hline Left upper limb & 0.096 & 0.621 & 0.108 & 0.578 & 0.093 & 0.633 \\
\hline \multicolumn{7}{|l|}{ Diastolic blood pressure $(\mathrm{mmHg})$} \\
\hline Right upper limb & -0.095 & 0.594 & 0.030 & 0.867 & -0.089 & 0.618 \\
\hline Left upper limb & 0.216 & 0.260 & 0.022 & 0.910 & -0.320 & 0.091 \\
\hline
\end{tabular}

$H A Q$, Health Assessment Questionnaire; rpb, the point biserial correlation coefficient; rho, Spearman correlation. Point-biserial correlation was used when one variable was continuous and the other dichotomy (e.g., yes or no, presence or absence).

Table IV - Fisher's exact test between vascular claudication and stenosis in upper limbs pressure in patients with Takayasu arteritis.

\begin{tabular}{|c|c|c|}
\hline \multirow{2}{*}{ Variables } & \multicolumn{2}{|c|}{$p$ value } \\
\hline & Right subclavian arterial stenosis & Left subclavian arterial stenosis \\
\hline \multicolumn{3}{|c|}{ Vascular claudication } \\
\hline Both upper limbs & 0.118 & 0.039 \\
\hline Upper right limb & 0.304 & 0.126 \\
\hline Upper left limb & $>0.999$ & 0.622 \\
\hline
\end{tabular}


As a hypothesis, this may be related to limb disuse associated with reduced functional capacity. Furthermore, patients at disease onset can suffer from novel limb claudication, pain, immobilization, or fatigue. Consequently, these negative experiences can be reflected in chronic reduction in strength and muscle mass, or in other mechanisms (27-29). However, further studies with large samples are needed to confirm our hypothesis.

Drug treatment, such as the use of glucocorticoids, may also interfere with strength and muscle mass (30). However, this possibility is remote since most of our patients used low-dose glucocorticoids.

Despite the higher prevalence of systemic arterial hypertension and dyslipidemia found in our series, when compared to the control group, and despite the use of statins that can produce muscle pain and calf cramps, mimicking the vascular claudication of the lower limbs (31-34), we evaluated the strength in the upper limb, reducing the interference of this confounding factor. Moreover, one study (32) shows that statins were not capable of promoting reduction in strength, muscle quality and volume.

Among the general population, reduced muscle strength may be a risk factor for negative long-term outcome; regardless of the individuals' level of physical activity or amount of lean mass, muscle quality (e.g., the ratio of strength to muscle area) is relevant for mortality (35).

Corroborating Metter et al. (35), Artero et al. (36) demonstrated that increased strength is related to reduced risk of cardiovascular disease, regardless of other factors such as body composition and aerobic capacity. In addition, reduced handgrip strength was correlated with increased risk of chronic diseases and mortality, and reduced long-term functional capacity $(35,37,38)$. In patients with systemic autoimmune diseases, impaired strength in this test is also related to reduced functional capacity or activities of daily living, thus corroborating our study's findings $(14,39)$.

To our knowledge, the study by Oliveira et al. (6) has been the only one to evaluate handgrip strength in TAK patients: these authors also found a reduced strength. However, the study did not analyze the differences in strength between limbs, their ratios, or correlations between handgrip, systemic blood pressure, vessel stenosis and vascular claudication. In our study, the difference in strength was evident in the left hand. Additionally, the difference between the hands was greater than $10 \%$, a value recognized as a limit of normality in the literature, suggesting to be a difference not caused by the right arm's dominance $(40,41)$. The reduction in strength in the left hand and the ratio between the hands found in our study also corroborate the results found for rheumatoid arthritis (25).

Our data showed a higher rate of vascular claudication when compared to stenotic lesions in the same limb, and these parameters did not correlate. In our hypothesis, the greater presence of "pseudo-claudication" (clinical but not pathologic changes) may be a consequence of the central nervous system dysfunction $(42,43)$ trigged by chronic limb pain, similar to that found in low back pain, osteoarthritis, fibromyalgia, headache, among others (42-45). All these diseases may also lead to low functional capacity. Additionally, studies show that pain can cause sensitization in the contralateral patients' limb $(46,47)$. Based on this assumption, the presence of claudication in one limb in our TAK patients could also cause "pseudo-claudication" in the contra-lateral patient's limb.

As the main limitation of the present study, we can cite the participant selection by convenience, providing increased selection bias. In addition, we included only patients with inactive disease and long disease duration.

The patients with TAK presented reduced left handgrip strength, as well as a reduction in the ratio between the non-dominant side over the dominant side. Grip strength was inversely related to the HAQ score of patients with TAK. This ultimately represented a reduction in the ability to perform activities of daily living. However, this reduction was not related to stenosis or blood pressure, and vascular claudication seemed not to be associated with subclavian artery 
stenosis in our sample. Further studies with large samples are needed to confirm our data.

\section{Funding}

This work was funded by Fundação de Amparo à Pesquisa do Estado de São Paulo (FAPESP) to MAS (\#2018/08735-3), RGM (\#2019/12155-5), and IBPB (\#2019/113679); Conselho Nacional de Desenvolvimento Científico e Tecnológico (CNPq) \#303379/ 2018-9, and Faculdade de Medicina da USP - SP to SKS.

\section{Conflict of interests}

All authors declare no conflict of interests.

\section{REFERENCES}

1. Lupi-Herrera E, Sanchez-Torres G, Marcushamer J, Mispireta J, Horwitz S, Vela JE. Takayasu's arteritis. Clinical study of 107 cases. Am Heart J. 1977; 93: 94-103.

2. Kerr GS, Hallahan CW, Giordano J, et al. Takayasu arteritis. Ann Intern Med. 1994; 120: 919-29.

3. Arend WP, Michel BA, Bloch DA, et al. The American College of Rheumatology 1990 criteria for the classification of Takayasu arteritis. Arthritis Rheum. 1990; 33: 1129-34.

4. Hata A, Noda M, Moriwaki R, Numano F. Angiographic findings of Takayasu arteritis: new classification. Int J Cardiol. 1996; 54: S155-63.

5. Rosa Neto NS, Shinjo SK, Levy-Neto M, Pereira RMR. Vascular surgery: the main risk factor for mortality in 146 Takayasu arteritis patients. Rheumatol Int. 2017; 37: 1065-73.

6. Oliveira DS, Shinjo SK, Silva MG, et al. Exercise in Takayasu arteritis: Effects on inflammatory and angiogenic factors and disease-related symptoms. Arthritis Care Res (Hoboken). 2017; 69: 892-902.

7. Pinto AJ, Miyake CN, Benatti FB, et al. Reduced aerobic capacity and quality of life in physically inactive patients with systemic lupus erythematosus with mild or inactive disease. Arthritis Care Res (Hoboken). 2016; 68: 1780-86.

8. Ekdahl C, Broman G. Muscle strength, endurance, and aerobic capacity in rheumatoid arthritis: a comparative study with healthy subjects. Ann Rheum Dis. 1992; 51: 35-40.

9. Alibaz-Oner F, Sreih AG, Merkel PA, Direskeneli H. Patient-reported outcomes in Takayasu's arteritis. Presse Med. 2017; 46: e225-27.

10. Aydin SZ, Merkel PA, Direskeneli H. Out- come measures for Takayasu's arteritis. Curr Opin Rheumatol. 2015; 27: 32-7.

11. Misra R, Danda D, Rajappa SM, et al. Development and initial validation of the Indian Takayasu Clinical Activity Score (ITAS2010). Rheumatology (Oxford). 2013; 52: 1795-801.

12. Fritsch S, Copes RM, Savioli B, et al. Translation and validation of the Indian Takayasu clinical activity score (ITAS2010) for the Brazilian Portuguese language. Adv Rheumatol. 2019; 59: 43.

13. Higgins SC, Adams J, Hughes R. Measuring hand grip strength in rheumatoid arthritis. Rheumatol Int. 2018; 38: 707-14.

14. Sferra da Silva G, De Almeida Lourenço M, De Assis MR. Hand strength in patients with RA correlates strongly with function but not with activity of disease. Adv Rheumatol. 2018; 58: 20 .

15. Carlson RV, Boyd KM, Webb DJ. The revision of the Declaration of Helsinki: past, present and future. Br J Clin Pharmacol. 2004; 57: 695-713.

16. Davies MJ, D’Alessio DA, Fradkin J, et al. Management of hyperglycemia in type 2 diabetes, 2018. A consensus report by the American Diabetes Association (ADA) and the European Association for the Study of Diabetes (EASD). Diabetes Care. 2018; 41: 2669-701.

17. American Diabetes Association. Diagnosis and classification of diabetes mellitus. Diabetes Care. 2014; 37: S81-90.

18. Whelton PK, Carey RM, Aronow WS, et al. 2017 ACC/AHA/AAPA/ABC/ACPM/AGS/ APhA/ASH/ASPC/NMA/PCNA Guideline for the prevention, detection, evaluation, and management of high blood pressure in adults: executive summary: a report of the American College of Cardiology/American Heart Association Task Force on Clinical Practice Guidelines. Hypertension. 2018; 71: 1269-324.

19. De Backer G, Ambrosioni E, Borch-Johnsen $\mathrm{K}$, et al; European Society of Cardiology Committee for Practice Guidelines. European guidelines on cardiovascular disease prevention in clinical practice. Third Joint Task Force of European and Other Societies on Cardiovascular Disease Prevention in Clinical Practice. Eur Heart J. 2003; 24: 1601-10.

20. Bruce B, Fries JF. The Stanford Health Assessment Questionnaire: dimensions and practical applications. Health Qual Life Outcomes. 2003; 1: 20.

21. Leng GC, Fowkes FG. The Edinburgh Claudication Questionnaire: an improved version of the WHO/Rose Questionnaire for use in epidemiological surveys. J Clin Epidemiol. 1992; 45: 1101-9.

22. Vischer AS, Burkard T. Principles of blood pressure measurement - current techniques, office vs ambulatory blood pressure measure- 
ment. Adv Exp Med Biol. 2017; 956: 85-96.

23. Williams B, Mancia G, Spiering W, et al. 2018 ESC/ESH Guidelines for the management of arterial hypertension. Eur Heart J. 2018; 39: 3021-104.

24. Lee P, Baxter A, Dick WC, Webb J. An assessment of grip strength measurement in rheumatoid arthritis. Scand J Rheumatol. 1974; 3: 1723.

25. Beumer A, Lindau TR. Grip strength ratio: a grip strength measurement that correlates well with DASH score in different hand/wrist conditions. BMC Musculoskelet Disord. 2014; 15: 336.

26. Moye L. Statistical methods for cardiovascular researchers. Circ Res. 2016; 118: 439-53.

27. Wall BT, Dirks ML, van Loon LJ. Skeletal muscle atrophy during short-term disuse: implications for age-related sarcopenia. Ageing Res Rev. 2013; 12: 898-906.

28. Seki K, Taniguchi Y, Narusawa M. Effects of joint immobilization on firing rate modulation of human motor units. J Physiol. 2001; 530: 507-19.

29. Rennie MJ. Anabolic resistance in critically ill patients. Crit Care Med. 2009; 37: S398-9.

30. Mastaglia FL. Adverse effects of drugs on muscle. Drugs. 1982; 24: 304-21.

31. Bruckert E, Hayem G, Dejager S, Yau C, Begaud B. Mild to moderate muscular symptoms with high-dosage statin therapy in hyperlipidemic patients-the PRIMO study. Cardiovasc Drugs Ther. 2005; 19: 403-14.

32. Panza GA, Taylor BA, Dada MR, Thompson PD. Changes in muscle strength in individuals with statin-induced myopathy: A summary of 3 investigations. J Clin Lipidol. 2015; 9: 351-6.

33. Thompson PD, Panza G, Zaleski A, Taylor B. Statin-associated side effects. J Am Coll Cardiol. 2016; 67: 2395-410.

34. Thompson PD. What to believe and do about statin-associated adverse effects. JAMA. 2016; 316: 1969-70.

35. Metter EJ, Talbot LA, Schrager M, Conwit R. Skeletal muscle strength as a predictor of allcause mortality in healthy men. J Gerontol A Biol Sci Med Sci. 2002; 57: B359-65.

36. Artero EG, Lee DC, Lavie CJ, et al. Effects of muscular strength on cardiovascular risk factors and prognosis. J Cardiopulm Rehabil Prev. 2012; 32: 351-8.

37. Hairi NN, Cumming RG, Naganathan V, et al. Loss of muscle strength, mass (sarcopenia), and quality (specific force) and its relationship with functional limitation and physical disability: The Concord Health and Ageing in Men Project. J Am Geriatr Soc. 2010; 58: 2055-62.

38. Rantanen T, Guralnik JM, Foley D, et al. Midlife hand grip strength as a predictor of old age disability. JAMA. 1999; 281: 558-60.

39. Dedeoglu M, Gafuroglu U, Yilmaz O, Bodur $\mathrm{H}$. The relationship between hand grip and pinch strengths and disease activity, articular damage, pain, and disability in patients with rheumatoid arthritis. Arch Rheumatol. 2013; 28: 69-77.

40. Petersen P, Petrick M, Connor H, Conklin D. Grip strength and hand dominance: challenging the 10\% rule. Am J Occup Ther. 1989; 43: 444-7.

41. Armstrong CA, Oldham JA. A comparison of dominant and non-dominant hand strengths. J Hand Surg Br. 1999; 24: 421-5.

42. Phillips K, Clauw DJ. Central pain mechanisms in chronic pain states-maybe it is all in their head. Best Practice Res Clin Rheumatol. 2011; 25: 141-54.

43. Phillips K, Clauw DJ. Central pain mechanisms in the rheumatic diseases: future directions. Arthritis Rheum. 2013; 65: 291-302.

44. Graven-Nielsen T, Arendt-Nielsen L. Peripheral and central sensitization in musculoskeletal pain disorders: an experimental approach. Curr Rheumatol Rep. 2002; 4: 313-21.

45. Nijs J, Malfliet A, Ickmans K, et al. Treatment of central sensitization in patients with "unexplained" chronic pain: an update. Expert Opin Pharmacother. 2014; 15: 1671-83.

46. Hosseinzadeh M, Samani A, Andersen OK, et al. Ipsilateral resistance exercise prevents exercise-induced central sensitization in the contralateral limb: a randomized controlled trial. Eur J Appl Physiol. 2015; 115: 2253-62.

47. Hedayatpour N, Izanloo Z, Falla D. The effect of eccentric exercise and delayed onset muscle soreness on the homologous muscle of the contralateral limb. J Electromyogr Kinesiol. 2018; 41: 154-9. 